\title{
Comparing the methods of oral hygiene, over hanged removal and restoration-Changing on periodontal health and alveolar bone height of rest orated mandibular molars with proximal over hanged amalgam
}

\author{
Masood Bamadi ${ }^{*}$, Mohammad Salarpour ${ }^{2}$ \\ ${ }^{1}$ Department of Periodontology, Zahedan School of Dentistry, Zahedan University of Medical Sciences, Zahedan, Iran; \\ *Corresponding Author: Bamadim@yahoo.com \\ ${ }^{2}$ Department of Endodontics, School of Dentistry, Zahedan University of Medical Sciences, Zahedan, Iran
}

Received 1 September 2013; revised 9 October 2013; accepted 17 October 2013

Copyright (C) 2013 Masood Bamadi, Mohammad Salarpour. This is an open access article distributed under the Creative Commons Attribution License, which permits unrestricted use, distribution, and reproduction in any medium, provided the original work is properly cited.

\section{ABSTRACT}

Objective: Conservative restoration principles that accurately reduce plaque accumulation are the goals of restorative dentistry. Correct and perfect restoration has an important effect on health of periodontious tissues. This study was done to compare the methods of oral hygiene, over hanged removal and restoration changing on periodontal health and alveolar bone height of restored mandible molars with proximal over hanged amalgam. Materials and Methods: All patients with over hanged amalgam restoration were randomly divided into three groups. In order to survey the effect of over hanged removal on gingival and bleeding indices and alveolar bone height adjacent to mandible molar teeth, these indices were determined according to recurrent radio-graphical early signs of alveolar bone loss during three months. Sixty patients, 20 in each group, were studied. In the group I, overhang was removed with ultrasonic scale or bur and oral hygiene methods as usual were continued. In the group II, over-hang was left, but plaque controls as the prophylaxis and flossing were done. In the group III, restoration was changed and oral hygiene was done as usual. Plaque index and bleeding index were measured at the beginning of study and three months later. Findings: Statistical analysis of studied indices at the beginning and three months after treatment using paired test has shown significant differences in gingival inflammation, in all groups. Statistical analysis of indices using Tukey HSD test has also shown significant differences in decreasing gingival inflammation measure when the over hanged restoration was removed. While there is no difference between the other two groups. Conclusion: The results showed that plaque control causes subsidence of gingival inflammation and increasing of alveolar bone support, and it is more effective when the over hanged restoration is changed.

Keywords: Amalgam; Over Hanged Margins; Gingival Health; Alveolar Bone Height

\section{INTRODUCTION}

Conservative restoration principles that accurately reduce plaque accumulation are the goals of restorative dentistry. Restoration should be adapted on dental anatomy in quality, proximal surfaces, embrasures, contour, and margin ends. The most important impact of restorations is their effect on hard and soft tissues surrounding the teeth. The gingival of under treating area prohibits dentist to be informed of contour situation and restoration margins and its biological adaptation with soft tissues in subgingival margins. The final purpose of dentist should be a sufficient restoration without damaging healthy tissues. Periodontal health shouldn't compromise and the existing disease heals [1].

Incorrect restorations such as proximal over-hang are 
often responsible for several pathological complications in dental tissues like gingival inflammation, bone loss and final loss of teeth while in sufficient restoration, soft tissue health and periodontal fibers are restrained or restored $[2,3]$.

According to definition, over-hang is an excessive amount of restorations which causes material protrude from the cavity and lead to plaque accumulation, decay and onset of periodontal diseases which commonly remain by dentist unconsciously. [4] over-hang can damage periodontal health in two ways:

1) Changing the ecologic balance in gingival sulcus and making an environment which allows growing of disease causative organisms often gram negative anaerobic species.

2) Plaque removing by patient becomes difficult in these areas [5,6]. For the importance of injuries which over-hang hits to the soft and hard oral tissues, this study was done in order to recognize better treating procedure for the restoration of teeth with proximal over-hang. The purpose of this study was to compare hygiene procedures, over hanged removal and restoration changing on periodontal health and bone height of restored mandible molars with proximal over hanged amalgam in patients who referred to Zahedan dentistry school in (20092010).

Materials and methods: the study was done in clinical practice before and after clinical trial on 60 male patients with an age range of 20 - 30 years (average age of 25.33 years) who referred to radiology and diagnosis department of Zahedan Dentistry School. Evaluation of all amalgam restoration was done in a dry, clean and illuminated environment. Studied variables included GI (gingival index).

And BI (bleeding index) and alveolar bone height clinical evaluation of amalgam restoration was done with visual observation, touching by explorer, flossing use and radiography interpretation. In clinical observation we used explorer 17 for over hanged evaluation, marginal fitness and superficial roughness of restoration. The contact area of amalgam with tooth was examined by moving tip of explorer forward and backward. If explorer tip traps in the joint and then removes toward amalgam suddenly, it means that there is over hanged. It also determined by trapping or tearing of flossing. Periodontal probe was used for determining bleeding severity of pocket next to restoration for studying the amount of bone loss and restoration conditions in the proximal surfaces repeatable intra oral radiographies were taken. The technique was paralleled with long cone and xсp film holder.

In xсp paralleling technique, the film is held in the teeth with putty impression material in order to fix the film in a suitable place for the next radiography which will be done 3 months later. The cases should have no systemic disease, and at least 1 year should have passed since the restoration time and the tooth which is in contact with the studying teeth must be intact.

Restoration should be above the alveolar crest and over-hang should be recognizable by flossing, radiography and explorer. For comparing different over hanged treatment methods, the patient shouldn't receive any oral hygiene instruction.

For surveying the effects of hygiene control method, over hanged removing and restoration changing on periodontal health and recurrent radiographic early signs of alveolar bone destruction during 3 months period, the patients were randomly divided into three groups, 20 in each group.

Group I: over-hang was removed by candle flame bur and oral hygiene continued as usual.

Group II: over-hang was left in place, but plaque control was done as prophylaxis and interdentally flossing.

Group III: restorations were changed and scaling was done in studying area and oral hygiene methods continued as usual.

Studying indices were surveyed at the beginning of study and 3 months later. Collected data were analyzed with SPSS ver. 17.

Findings: results in age, gingival index, bleeding index and bone regeneration measure in studying groups and comparisons of groups were as follows:

The average age in oral hygienic, over hanged removal and restoration change groups were 24.90, 25.30, and 25.80 years, respectively.

According to ANOVA analysis, there were significant differences between averages $(p>0.05)$.

Restoration change group:

In restoration changed group, gingival average indexes before and after treatment were $2.27,1.50$, respectively. According to paired T-T Test analysis, there is a significant difference between average $(\mathrm{p}=0)$ (Table 1).

In this group, bleeding average indexes before and after treatment were 2.17 and 1.40 , respectively.

According to paired T-T Test analysis, there is a sig-

Table 1. Average and standard deviation of gingival index and early bleeding index and after three months in restoration changed group.

\begin{tabular}{|c|c|c|c|}
\hline Variable & $\begin{array}{c}\text { Standard } \\
\text { deviation }{ }^{\#} \text { average }\end{array}$ & Number & Average error \\
\hline Early gingival index & 2.2750 & 20 & 0.16008 \\
\hline Later gingival index & 1.5000 & 20 & 0.14434 \\
\hline Early bleeding index & 2.1750 & 20 & 0.11815 \\
\hline Later bleeding index & 1.4000 & 20 & 0.10000 \\
\hline
\end{tabular}


nificant difference between averages $(p=0)$ (Table 1). Hygienic control group:

In hygienic control group, gingival average indexes before and after treatment between cases were 2.62, 2.12, respectively.

According to paired T-T Test analysis, there is a significant difference between averages $(p=0)$ (Table 2).

In this group, bleeding average indexes between the cases, before and after treatment were 2.40 and 1.92 respectively.

According to paired T-T Test analysis, there is a significant difference between averages $(\mathrm{p}=0)$ (Table 2).

Over-hanged removal group:

In over hanged removal group, gingival average indexes before and after treatment were 2.32, 1.90, respectively.

According to paired T-T Test analysis, there is a significant difference between averages $(p=0)$ (Table 3).

Bleeding average indexes between before and after treatment cases were 2.42 respectively. According to paired $\mathrm{T}-\mathrm{T}$ Test analysis, there is a significant difference between averages $(p=0)$ (Table 3$)$.

\section{DISCUSSION}

The result showed that effect of different treatment method on the studying indices and alveolar bone height has little but measurable healing improvement. If the study had gone longer time, more improvement might have been occurred both on the alveolar bone height and on the indices.

These changes are proportional marginal bone osteo-

Table 2. Average and standard deviation of early gingival and bleeding indices and three months after treatment in hygienic control group.

\begin{tabular}{cccc}
\hline Variable & $\begin{array}{c}\text { Standard } \\
\text { deviation }{ }^{\#} \text { average }\end{array}$ & Number & Average error \\
\hline Early gingival index & 2.6250 & 20 & 0.23938 \\
Later gingival index & 2.1250 & 20 & 0.24791 \\
Early bleeding index & 2.4000 & 20 & 0.19791 \\
Later bleeding index & 1.9250 & 20 & 0.19021 \\
\hline
\end{tabular}

Table 3. Average and standard deviation of early gingival and bleeding indices and three months after treatment in over hanged removal group.

\begin{tabular}{cccc}
\hline Variable & $\begin{array}{c}\text { Standard } \\
\text { deviation }{ }^{\#} \text { average }\end{array}$ & Number & Average error \\
\hline Early gingival index & 2.3250 & 20 & 0.10574 \\
Later gingival index & 1.9000 & 20 & 0.13017 \\
Early bleeding index & 2.4000 & 20 & 0.17559 \\
Later bleeding index & 2.0000 & 20 & 0.17873 \\
\hline
\end{tabular}

poros is that seen as bone loss in radiography. Removing the etiologic factor will result osteoporotic bone remineralization and refilling or increase height of bone. This doesn't mean that in bone lost areas new osteoidbone will deposit. But can occur in the infra pocket defects. ANOVAs analysis showed that in the different treatment methods, there is no significant difference between groups in age variable. This is an advantage in our study in the treatment procedures, Amalgam restoration changed group with proximal over hanged, and average age was 24.90 years and had the most improvement studying indices. In this group the average amount of bone regeneration was improved up to $0.21 \mathrm{~mm}$, gingival index. 0.77 and bleeding index up to $0.7 \mathrm{~mm}$. Restoration changing provides much more efficient plaque control which leading in decreasing gingival inflammation and increasing alveolar bone height. Also decrease caries in restoration margin, which in turn improve plaque control.

In plaque control group without over hanged removing, average age was 25.8 years, average amount of bone regeneration $0.16 \mathrm{~mm}$, and gingival index. 0.5 and bleeding index $0.47 \mathrm{~mm}$ was improved. In this group irregularities in restoration margins result in wear and tear off lossing and adequate plaque control could not be preformed. This is the reason that in this group we had a lower improvement in the studying indices and the alveolar bone height.

This shows that damaging impact of the over-hanged restorations is basically because of its effect. Increasing plaque retention does not cause mechanical injury and this result in less improvement in gingival and periodontal tissue in comparison with restoration changed group.

In this regard, this study is matched with Highield and Powell results [7].

In group in which over hanged was removed with a bur, and oral hygiene was performed as usual method, the average age of the patients was 25.30 years and the lowest improvement in all indices and alveolar bone height was seen in this group. So, average amount of bone regeneration was $0.14 \mathrm{~mm}$, gingival index. 0.42 and bleeding index was $0.40 \mathrm{~mm}$. Because the gingival in the treating area prevent good visualization of dentist, he cannot be informed of contour situation and restoration margins. Thus cannot be informed about its biocompatibility with the soft tissues. Therefore, does not remove over hanged margins properly. This result gingival damage and scratches and grooves both on the restoration and tooth surface.

Calculus and microbial plaque remain under over hanged and develop in occumulation. On the other hand, because of inadequate amalgam packing in over hanged cases, there is no adaptation between restoration and tooth margin. This result in more and more plaque retention as gingival inflammation. However, the inflamma- 
tion level in comparison with the beginning of the study was lower, and which was in line with Powell-Highfield (1978), Ferrer-Rodriquez (1980) and Roman-Torres (2006) [7-9] results.

\section{CONCLUSION}

This study showed that restoration changing for proximal over hanged amalgam resulted in the most improvement of proximal gingival health and increased alveolar bone support.

\section{ACKNOWLEDGEMENTS}

We express our gratitude for the financial support given by our University for conducting our research Project, and our heart-full thanks to those who contributed their valuable time in assisting with us.

\section{REFERENCES}

[1] Shugars, D.A. and Shugars, D.S. (2002) Patient assessment, examination and diagnosis and treatment planning. In: Roberson, T.M. and Heymann, H., Eds., Sturdevant's Art and Science of Operative Dentistry, 4th Edition, The CV Mosby Co., Louis, 409.

[2] Parsell, D.E., Streckfus, C.F., Stewart B. and Buchanan, W.T. (1998) The effect of amalgam over hanged on alveolar bone height as a function of patient age and over hanged width. Operative Dentistry, 23, 94-99.

[3] Pack, A.R.C., Coxhead, L.J. and Mcdonald, B.W. (1990)
The prevalence of 0ver hanged margins inposterior amalgam restoration and periodontal consequences. Journal of Clinical Periodontology, 17, 145-152. http://dx.doi.org/10.1111/j.1600-051X.1990.tb01078.x

[4] Brunsvold, M.A.I. and Lane, J.J. (1983) The prevalence of over hanged dental restorations and their relation ship to periodontal disease. Journal of Clinical Periodontology, 10, 563-578.

[5] Lang, N.P. and Kieira, A. (1983) Clinical and microbeological effects of subgingival restorations with over hanged or clinically prefect margins. Journal of Clinical Periodontology, 10, 563-578. http://dx.doi.org/10.1111/j.1600-051X.1983.tb01295.x

[6] Newman, M.G. and Carranza, F.A. (2006) Clinical periodontology. 10th Edition, Sunders Co., 177.

[7] Highfield, J.E. and Powell, R.N. (1998) Effects of removal of posterior over hanged margins of restorations upon the periodontal tissues. Journal of Clinical Periodontology, 5, 169-181. http://dx.doi.org/10.1111/j.1600-051X.1978.tb02277.x

[8] Rodriguez-Ferrer, H.J., Strahan, J.D. and Newman, H.N. (2005) Effect on gingival health of removing margins of interproximal subgingival amalgam restorations. Journal of Clinical Periodontology, 7, 457-462. http://dx.doi.org/10.1111/j.1600-051X.1980.tb02152.x

[9] Roman-Torres, G., Barata, D.A. and Romeiro, A. (2006) A short-term clinical and microbial evaluation of periodontal therapy associated with amalgam over hanged removal. Journal of Clinical Periodontology, 77, 15911597. http://dx.doi.org/10.1902/jop.2006.050145 